Issued by Sandia National Laboratories, operated for the United States Department of Energy by Sandia Corporation.

NOTICE: This report was prepared as an account of work sponsored by an agency of the United States Government. Neither the United States Government, nor any agency thereof, nor any of their employees, nor any of their contractors, subcontractors, or their employees, make any warranty, express or implied, or assume any legal liability or responsibility for the accuracy, completeness, or usefulness of any information, apparatus, product, or process disclosed, or represent that its use would not infringe privately owned rights. Reference herein to any specific commercial product, process, or service by trade name, trademark, manufacturer, or otherwise, does not necessarily constitute or imply its endorsement, recommendation, or favoring by the United States Government, any agency thereof, or any of their contractors or subcontractors. The views and opinions expressed herein do not necessarily state or reflect those of the United States Government, any agency thereof, or any of their contractors.

Printed in the United States of America. This report has been reproduced directly from the best available copy.

Available to DOE and DOE contractors from

U.S. Department of Energy

Office of Scientific and Technical Information

P.O. Box 62

Oak Ridge, TN 37831

Telephone: (865)576-8401

Facsimile: (865)576-5728

E-Mail: reports@adonis.osti.gov

Online ordering: http://www.doe.gov/bridge

Available to the public from

U.S. Department of Commerce

National Technical Information Service

5285 Port Royal Rd

Springfield, VA 22161

Telephone: $(800) 553-6847$

Facsimile: (703)605-6900

E-Mail: orders@ntis.fedworld.gov

Online order: http://www.ntis.gov/ordering.htm

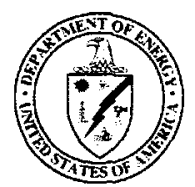




\section{DISCLAIMER}

Portions of this document may be illegible in electronic image products. Images are produced from the best available original document. 
SAND2000-1134

Unlimited Release

Printed May 2000

\title{
Fast Pragmatic Safety Decisions: Analysis of an Event Review Team of the Aviation Safety Action Partnership
}

\author{
John H. Ganter and Craig D. Dean \\ Distributed Information Systems \\ Bryon K. Cloer \\ Laboratory Science and Technology \\ Sandia National Laboratories \\ P. O. Box 5800 \\ Albuquerque, New Mexico 87185 \\ Email contact: jganter@sandia.gov
}

\begin{abstract}
Commercial aviation has become safe as a result of procedures and technologies that control wellknown hazards. Further safety improvements will require the identification of subtle and changing hazards in the combined realm of airspace, technology, commerce, and human behavior. The preconditions for a disaster may arise from the combined effects of a particular airport approach, air traffic control policies, and aircraft crew training. The potential may be revealed just once, in a near-miss that a highly skilled pilot is able to avert. Yet, because such discoveries are often related to human error, personnel are reluctant to come forward for fear of blame and punishment. With the Aviation Safety Action Programs (ASAP), the Federal Aviation Administration (FAA) is developing a nonpunitive collaborative approach that supplements traditional regulatory actions. An ASAP team is a triad composed of air carrier (corporate), pilot association (union), and FAA (regulatory) personnel who meet to review, discuss, and analyze event reports submitted voluntarily by flight personnel. The team is required to reach "unanimous consensus" on the event report and the corrective actions to be taken. Our analysis suggests they do so through a hierarchy of shared values, a working buffer to exclude distractions, and sideband communications that build trust. ASAP appears to be a highly effective cultural mechanism for identifying novel and subtle hazards, and designing rapid, mutually acceptable corrective actions.
\end{abstract}




\section{Acknowledgements}

This report is an account of independent research sponsored by the Flight Standards Service (AFS) of the Federal Aviation Administration. The opinions are those of the authors and do not necessarily reflect those of other individuals or organizations.

We thank the event review team participants for allowing us to observe their meetings, and answering our questions about the process. We thank the following people for their comments on drafts of this report: Tom Chidester, Kathleen V. Diegert, K. Scott Griffith, Patty G. Guyer-Stevens, Roger D. Hartman, Keith S. Jones, Kenneth W. Kadey, and Bruce N. Malm. David R. Fletcher contributed to the early development of this approach. 


\section{Contents}

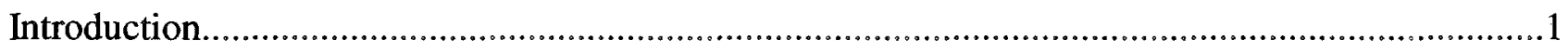

The FAA Aviation Safety Action Programs (ASAP) . ........................................................2

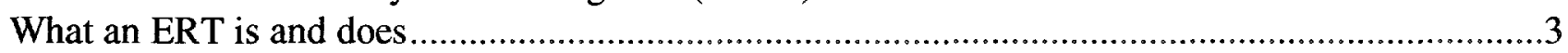

Event reports from the field .......................................................................................... 3

Visible structure and behavior of the ERT .................................................................

Continuously constructing the Unanimous Consensus ...................................................... 7

How the ERT works as an institution of a safety culture ......................................................9

The challenge facing the ERT: What are we seeing and what does it mean? ...........................9

The ERT looks for cues in complex phenomena............................................................. 11

A tilt-table model of ERT collaboration .......................................................................12

Achieving table balance: The AA-ASAP Hierarchy of Values ............................................13

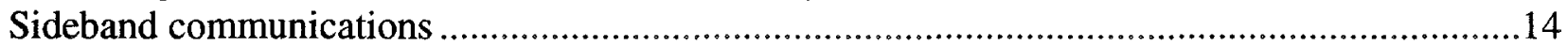

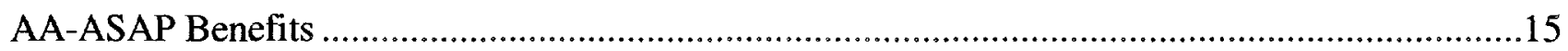

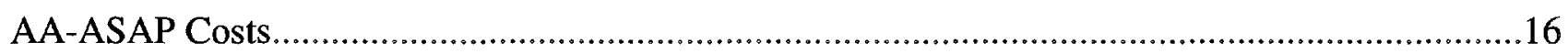

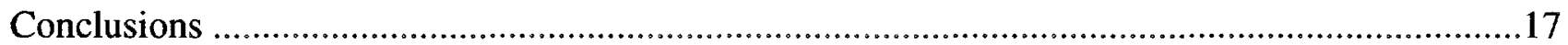

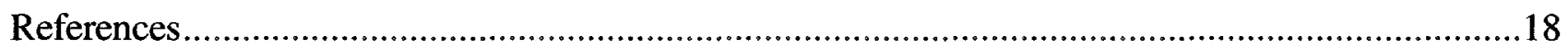


This page intentionally left blank 


\section{Introduction}

Technology and know-how have reduced the accident rate of aviation to low levels. But it is widely recognized that new approaches will be needed to lower the rate further (Grey, 1999). An airline executive comments that:

Regardless of the marvelous innovations in technology and procedures ... we're not going to slash the accident rate until we get our front-line employees in the mindset to give us the information we need.

(McKenna, 1999).

To encourage this information flow we will have to improve safety culture: the shared beliefs, values, procedures, and skills that allow people to jointly identify and respond to subtle hazards.

The most common barrier to this reporting is fear of prosecution or disciplinary action by an employer. Regulatory enforcement has tended to group criminal wrongdoing with the honest mistakes that professionals make. This discourages the reporting of mistakes that reveal system weaknesses and new hazards. While the individual may learn something from the event, the larger community of aviators does not. Further, corrective action can not be taken if the small events that presage larger accidents are never brought to the attention of management.

By promoting the Aviation Safety Action Programs (ASAP), the Federal Aviation Administration (FAA) has recognized the potential value of regulators working collaboratively with the aviation industry to collect, understand, and act on event reports. Some of the event reports are unwitnessed, self-reported violations. Many event reports, however, are not of violations. These events are glimpses, often novel, of emerging and/or subtle hazards in aviation. By discovering, understanding and acting on such small events in a non-punitive manner, ASAP can perhaps prevent true violations and accidents from occurring. Thus ASAP may be an effective supplement to ongoing FAA enforcement programs. This raises the questions of how ASAP works and the benefits and costs of instituting it more broadly.

This report analyzes a Flight Department ASAP Event Review Team (ERT) as a safety culture microcosm. We examine the group's process and dynamics, not the confidential events that it deals with. First, we look at what an ERT does, the people who attend, how they interact, what they discuss, what information they consult, and the decisions they reach. How does the team relate what it perceives (an event report) to collective aviation wisdom and belief (in particular the Federal Aviation Regulations (FARs))? What is the significance of the "unanimous consensus," and how does the team continually regenerate it?

Next, we look deeper into the ERT and build a model of how it works. We show that the ERT addresses three fundamental questions: (1) What are we seeing in this event? (2) What does it mean and imply? (3)What should the ERT do about it? This interpretation process produces continuous and productive conflict between the team members. We show how these conflicts are resolved by the end of each event discussion, and the stability of the team maintained. In the concluding sections, we look at the apparent benefits, both direct and indirect, of the ERT process to the larger safety culture. 


\section{The FAA Aviation Safety Action Programs (ASAP)}

Safety regulation has traditionally been punitive, drawing its approach from civil and criminal law. There has often been an assumption of negligence or recklessness in the commission of error and the occurrence of accidents (Reason 1997, p. 207). But today it is often recognized that highly skilled "professionals can and will make mistakes, regardless of regulatory prohibitions" (Griffith and Marx, 1998).

Provided that negligence and recklessness are absent, errors can be incomparable opportunities for learning. Over time, dealing with error in a constructive manner can raise both individual and organizational proficiency, accomplishment, and morale. For example, researchers who have studied "high reliability organizations" such as aircraft carriers (Rochlin, La Porte and Roberts, 1987) find that there is a

willingness to reward the discovery and reporting of error, without at the same time pre-emptorially assigning blame from its commission. This obtains even for the reporting of one's own error in operations and procedural adherence. The premise is that it is better and commendable for one to report an error immediately than to ignore or cover it up.

(La Porte 1996, p. 64).

This lessons-learned approach in military aviation has influenced civilian aviation. Since the mid1970s, the Air Safety Reporting System (ASRS) has collected tens of thousands of event reports. In ASRS, "the extent of mea culpa in the reports is striking, as is the objectivity of the analysis" (Perrow 1984, p. 169). While highly beneficial, the limitation of ASRS and similar programs has been the weak connection between lessons-learned and corrective action. Those in the best position to correct problems may not become aware of them in a timely manner.

Regulators and commercial air carriers are now working to combine event reporting, analysis, and corrective action. In an Advisory Circular to aviators, the FAA has announced that

The FAA and the air transportation industry have sought alternative means for addressing safety problems and identifying potential safety hazards. To this end, the FAA, in cooperation with industry, [will establish] several demonstration ASAP in an effort to increase the flow of safety information to both the air carrier and FAA.

(FAA AFS-200, 1997).

The aim of the programs is corrective action to prevent recurrences of events and possible escalations to accidents. Both FAA and carrier management emphasize corrective action, rather than punishment, in order to cast a wide net for event reports.

ASAP is a management framework that relates safety goals to program rules (e.g. the conditions for punitive action) and a process outline. The details of each program are to be worked out between the parties and agreed to in a memorandum (McKenna, 1999; Mathews, 2000). 
In 1999 when we performed our analysis, the only such program was in place at American Airlines. At American it is called the "Aviation Safety Action Partnership," another "ASAP" acronym. ${ }^{1}$ In this report, we designate this "AA-ASAP" to distinguish it from the larger FAA ASAP initiative.

We analyze one part of AA-ASAP in detail, the Event Review Team (ERT) that addresses flight events. (Other AA-ASAP programs address maintenance and dispatch.) This analysis will show how the ERT functions and look for any innovations or problems within the ERT that could inform the larger FAA ASAP initiative.

A note on our analytical approach: Many regulatory programs have very complex rules and procedures that lead to relatively simple interactions among people. AA-ASAP, in contrast, has a few simple rules that seem to result in a complex, and subtle, safety culture. Thus a purely reductionist analysis of AA-ASAP risks missing the forces that make it work. In order to understand the social mechanisms of this culture, we had to take a somewhat unconventional approach. We adopted journalistic and anthropological styles of analysis. First, we briefly describe the setting, dialog, and visible behavior of the ERT to give the reader a narrative sense of what it is like to be in an ERT meeting. We then look more closely at the underlying cultural values and mechanisms.

\section{What an ERT is and does}

Event reports from the field

In a domain as complex and far-reaching as aviation, things occasionally go wrong in ways that are not always obvious. Under AA-ASAP, "all eligible employees are encouraged to report any event or observation that they feel identifies a potential hazard to flight operations and should be reviewed by the ERT" (AA-ASAP, 1998). These reports run the gamut from terse, two-sentence altitude deviations to complex chains of events - in rare cases with an accident as an outcome.

Reports must be submitted within 24 hours of the event. They can be telephoned, emailed, or faxed to the AA-ASAP program. As the sample shows (Figure 1), the reports are typically narrated in a terse, first-person style by pilots and crew members. American Airlines de-identifies the reports and forwards them simultaneously to the ERT members.

\section{Visible structure and behavior of the ERT}

The Flight Department ASAP ERT meets weekly at the American Airlines Academy in Fort Worth, Texas. The team's job is to review new event reports, discuss new information on active reports, and decide on actions to take.

\footnotetext{
${ }^{1}$ The American Airlines ASAP was implemented in 1994 (Griffith and Marx, 1998; Helmreich and Merritt, 1998). The FAA ASAP initiative is partly based on the continuing American Airlines ASAP.
} 
The team assembles around a large table. The FARs and other manuals are on the table or close at hand. There is a telephone available to make inquiries, but it does not ring. The room is quiet, and the doors are kept closed except as people come and go.

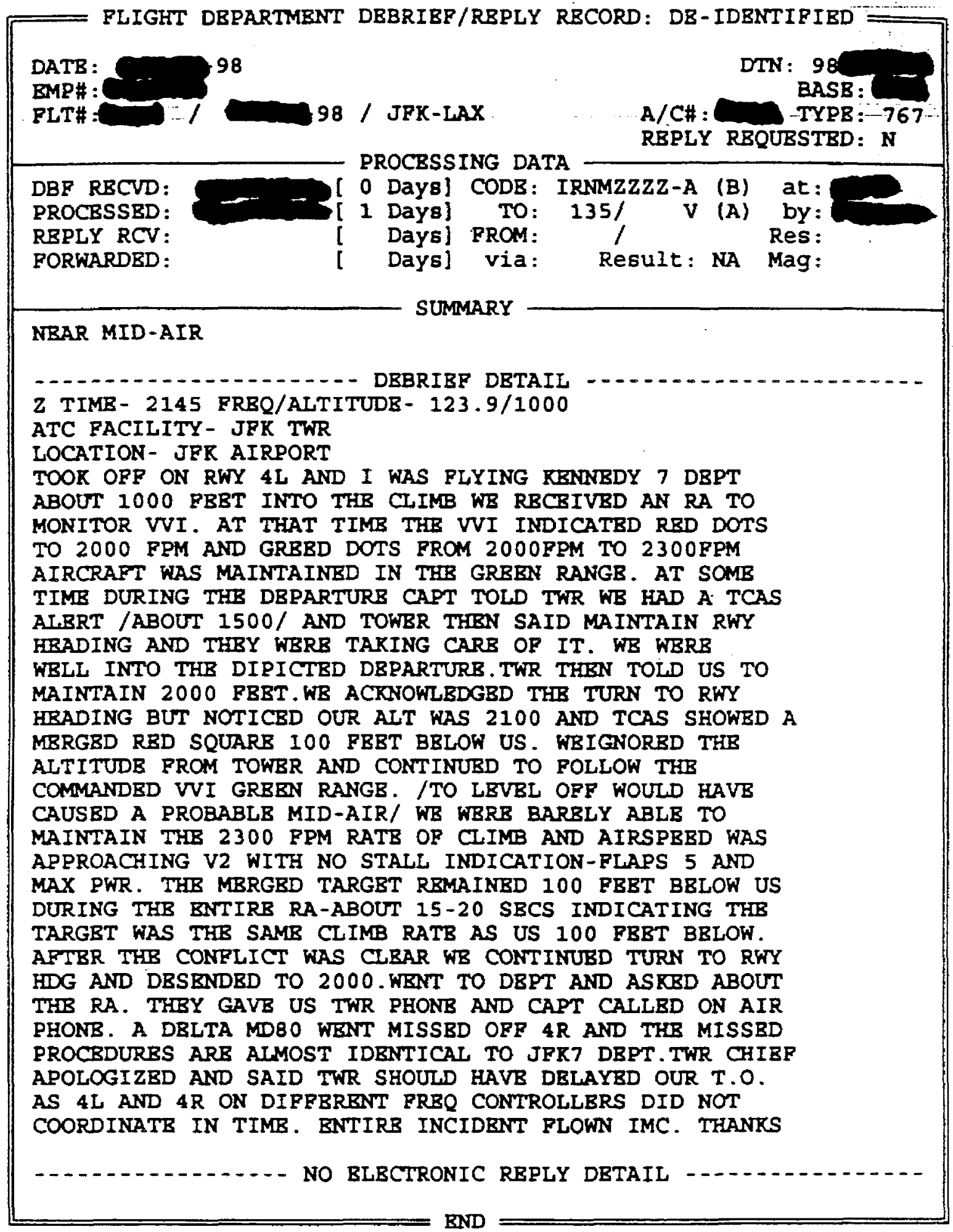


Figure 1. Sample AA-ASAP event report, with confidential information redacted. Reproduced from AA-ASAP Letters of Agreement (AA-ASAP, 1998).

The three participants forming the inner circle of the ERT gather (Figure 2). They represent the FAA, American Airlines, and the Allied Pilots Association (APA). Each carries a thick three-ring binder containing the event reports. New reports have been distributed to the team members in advance of the meeting. Thus when the meeting begins, the event reports are either old business (they have been discussed before) or new business (the participants have seen them, and perhaps done some fact finding, but they have not discussed them yet).

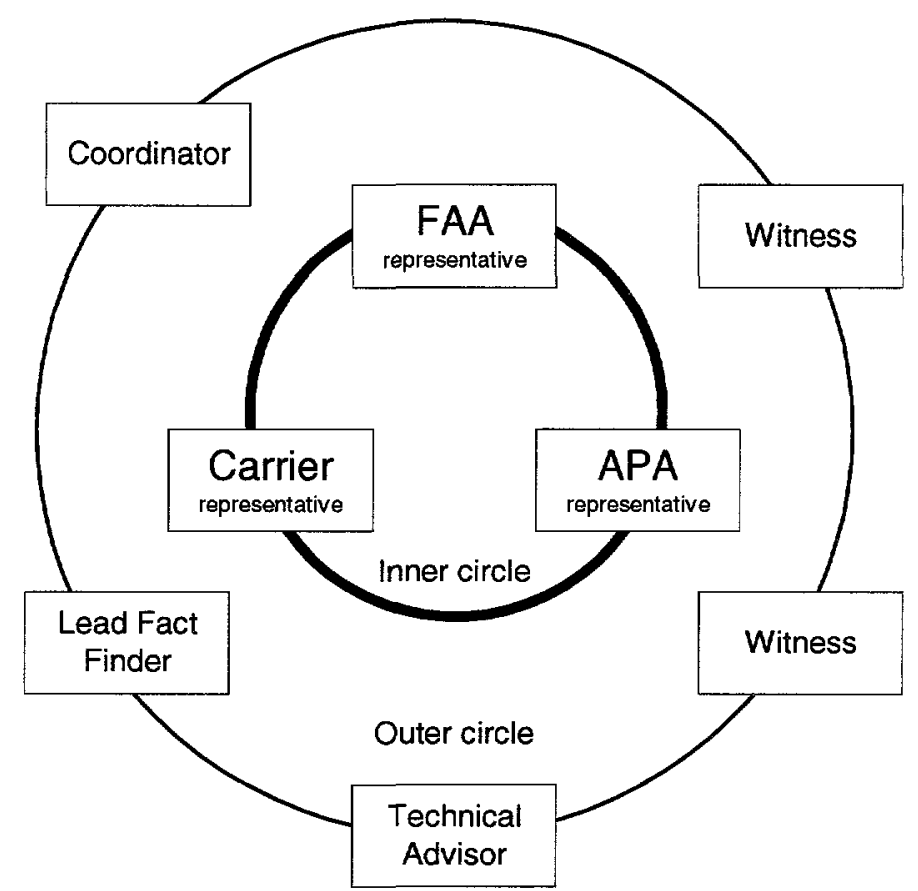

Figure 2. The ERT represented as an inner circle consisting of the three representatives, and an outer circle that provides information, opinions, and other process support. This is a schematic diagram, not a literal map of the ERT meeting.

A knowledge infrastructure surrounds the inner circle. A coordinator serves as secretary to the group, tracking the resolution of events and taking notes on the official correspondence to be created. The coordinator obtains information and schedules visits by witnesses. The coordinator also serves as a point of reference. When the team members finish discussing a very complex report, the coordinator often provides status information (e.g., new information obtained, arrival of witnesses, etc.).

The outer circle also includes a varying collection of witnesses, technical advisors, and fact finders. Witnesses describe what they saw and/or did in connection with a particular event. Technical advisors provide specific information and interpretations of the circumstances and details of an event. For example, an avionics advisor may provide an operational history of a particular fielded system. 
One or more fact finders are asked or volunteer to locate specific details that are needed by the team. The fact finders often leave the room, returning in minutes or hours with key information about an event. The fact finders are experts at navigating the knowledge infrastructure of the aviation domain. At a minimum, they know whom to call to begin a search.

The meeting begins. Everyone turns to the first event under old business. It is an altitude deviation involving miscommunication between an aircrew and ATC (air traffic control). New information has been discovered. Participants read their notes aloud to emphasize details. They recount telephone conversations. The fact finders speak up to clarify.

Periodically, disagreement arises. The APA representative may believe that a pilot is being blamed unfairly. The representative staunchly defends their union member. Or the FAA representative may believe that a rule is perfectly clear when the other representatives find it ambiguous. An event may suddenly raise issues that have been in the courts and/or news media.

AA-ASAP requires progress, so a compromise must be reached. A decision is proposed. The lead looks around. The others in the inner circle nod assent. The event is resolved, and a corrective action decided on. In unison, each team member tears the page from his or her binder. The pages go into a pile at the center of the table, to be shredded later. To an observer, the tearing seems to be a small celebration of resolution and moving on. ERT meetings are draining, but the growing pile of pages provides a tangible indicator of progress.

Some events are complex and ambiguous. They are system phenomena that may involve "causal contributions from many different people distributed widely both through the system and over time" (Reason 1997, p. 8). Interpretation and judgment are required. The team becomes more animated. They put down the binders and look at each other and members of the outer circle. What does this mean? Why do you think so? Are you sure? Can you show me? Do we need more information? What information? Where might we find it?

These actual dialogue samples give a sense of the ebb and flow of the ERT process:

- Would you be able to check...

- I'll call and double-check...

- Do we know why the engine was changed? How could we find that out?

- I don't know that we've seen...

- Do we know if it flew in between? Why?

- I just want to think about the guidance we want to leave [i.e., what lesson do we want to publish as a result of this event]

- Maybe he [the employee] should have known. I don't know. I just don't know.

- Another one! Another one! [reaction to an approach event at a specific airport]

- You guys have aviation backgrounds? [to visitors during a lull]

The members articulate and deliberate. They interpret ambiguous phenomena that are only partially captured in the event reports. They make inferences from limited data. They share unique perspectives from their professions and individual histories. They respect each other's differences 
of background and constituencies. They try to let the facts, if they can be uncovered, speak for themselves.

To an outside observer, the ERT is an impressive hybrid combining aspects of jurisprudence, management, science, engineering, and detective work. Later in this report we will take a closer look at the social mechanisms that seem to make this hybrid function.

Regulations play a pivotal role for the ERT and are used for guidance and as a tiebreaker to resolve differences. In our observations, the FARs and other documents are consulted frequently. But they are not subject to tug-of-war. Instead, they are shared in turn. At a particular point in a discussion, the team quickly (and often silently) decides who should consult the documents. The person does so, finds the section, and quotes aloud. Skill at "knowing the FARs" and being able to quickly locate sought sections seems to be highly respected.

\section{Continuously constructing the Unanimous Consensus}

To an observer, one of the most interesting features of AA-ASAP is the unanimous consensus. The meaning and importance of the concept is suggested by the following statements from the AAASAP Letters of Agreement (1998):

The success of [AA-]ASAP is built on the trust and cooperation of the ERT in achieving a unanimous consensus on each event that is reported.

A unanimous consensus is defined as the voluntary agreement of all three ERT representatives.

The unanimous consensus ... does not require that all members believe that a particular decision or recommendation is the most desirable solution, but that the result falls within each member's range of acceptable solutions for that event and for continued program participation.

The phrase "unanimous consensus" strikes some as redundant. Indeed, the complete definitions ${ }^{2}$ of the two words overlap:

con.sen.sus n, often attrib [L, fr. consentire] (1858) 1 a: general agreement: unanimity $b$ : the judgment arrived at by most of those concerned $<$ the $\sim$ was to go ahead $>2$ : group solidarity in sentiment and belief

unan.i.mous adj [ $\mathrm{L}$ unanimus, fr. unus one + animus mind--more at one, animate] (1624) 1: being of one mind: agreeing 2: formed with or indicating unanimity: having the agreement and consent of all

\footnotetext{
${ }^{2}$ Definitions are from the Merriam-Webster Dictionary, 1994.
} 
To the AA-ASAP managers, however, the complete phrase is meaningful in a way that the individual words are not. They believe the concept is an essential foundation of the program.

We interpret unanimous consensus as a process test point. It is a decision guideline. The phrase combines two specific meanings of the words to create a practical conceptual hybrid.

Consider the following ERT process outline:

Step 1: The team, with diverse and inherently conflicting backgrounds, meets to understand events and take actions. The team exhibits meaning (2) of consensus: "group solidarity in sentiment and belief." Broadly, they have a common goal: actions to increase safety. There is nothing to disagree about - yet.

Step 2: The team now confronts a specific event. There is ambiguous evidence subject to different interpretations. The different values of the team members come into play. Deadlock is a hazard. Dominance by one party to the detriment of the others is another hazard. The team may be unable to agree on action. The general consensus of Step 1 may be immobilized by the sticky details of a specific event.

Step 3: The rules of the process demand joint action, or the whole AA-ASAP process ends. This test point must be passed. The team must achieve unanimous consensus, using meaning (2) of the word: "having the agreement and consent of all."

Step 4: A compromise is reached. The team members cannot agree perfectly, but "the result falls within each member's range of acceptable solutions for that event and for continued program participation" (AA-ASAP 1998, p. 8). The test point has been passed, and the team is now ready to confront the next event.

Thus we believe the phrase unanimous consensus, in the context of AA-ASAP, is not redundant. It is a test that constantly maintains the stability of the overall AA-ASAP process (Figure 3 ). The result is a series of good, productive decisions - they lead to pragmatic administrative actions that reflect the way things "ought to be" (Simon 1945/1997, p. 57).

Many cooperative programs undergo a gradual decline that has no clear beginning. The onset of the demise of the program is gradual and subject to varying interpretations. Meetings start to drag. Members begin to have plausible but oddly recurring time conflicts. By the time the dimensions of the problem are recognized, it may be too late for successful intervention.

AA-ASAP binds actions to their consequences. By insisting on consensus for every event, it maintains a constant connection to its fundamental values. These values provide power (they insist on action) and avoid hazards (they connect immediate actions with the long-term health of the process). 


\section{How the ERT works as an institution of a safety culture}

We have described the general structure of an ERT meeting and given a sense of how the action unfolds. We will now look at the ERT in more detail, relating its mechanisms to theories of system safety and culture.

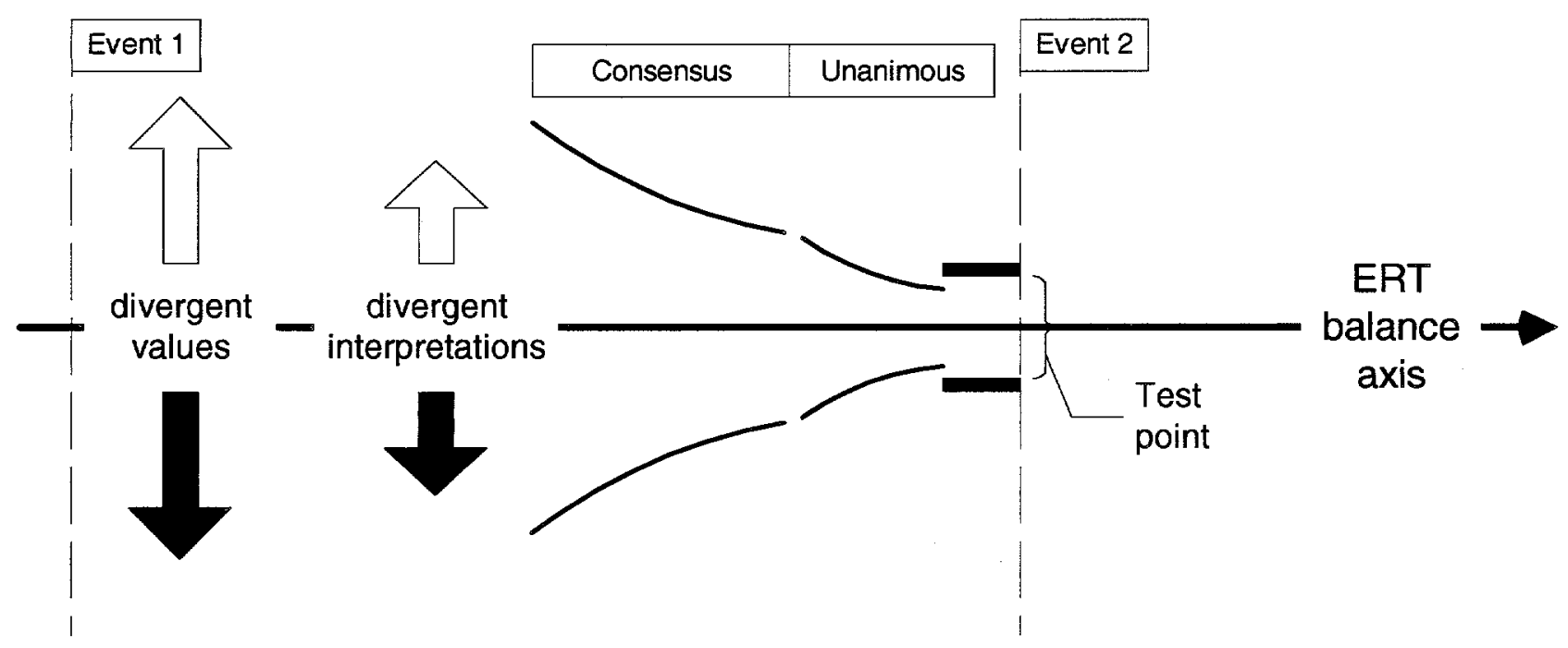

Figure 3. Conceptual diagram of an ERT meeting as a series of event reports. The divergent viewpoints of the participants begin to converge with general consensus. The process rules then demand that they converge still further with a unanimous consensus for action. This test preserves the long-term stability of the ERT process, and insures that one point of view does not dominate.

The challenge facing the ERT: What are we seeing and what does it mean?

Many event reports are straightforward and repetitive. They are important, however, as reminders that hazards, including complacency, are always present in the aviation domain (see Reason 1997, p. 114; Leveson 1995, p. 54).

Some event reports are cryptic. Yet, the expert making the report did so because they sensed that something significant had occurred. Perhaps they noticed a subtle detail that seemed wrong or out of place. The warning light blinked once. Or their expectations about a situation may have been disrupted - they expected A to happen and instead B happened. Something did not fit their mental patterns of how the aviation domain works and the hazards within it (see Klein 1998, p. 149).

Education researchers have noted that this type of surprise is an essential precursor to learning. But the valid lesson to be drawn may not be obvious in a domain as complex as aviation. So the expert files an event report in order to bring more minds to bear on the situation.

Neither the event reporter nor the ERT are omniscient. They may have caught a glimpse of a near accident, or it may have been a minor anomaly. If the meaning of the event is ambiguous, it will be difficult to reach unanimous consensus on correction action. Ambiguity usually has two sources: uncertainty and equivocality. 
- Uncertainty comes from a lack of information. The ERT reduces uncertainty by using witnesses, experts, and the fact finders to discover what happened in an event. These sources allow the ERT to draw evidence into, they hope, a single meaning. From this meaning, lessons can be drawn and corrective actions taken. But the event reporter may not be able to do this or may not have the authority.

- In equivocality, "the problem is that there are too many meanings, not too few" (Weick 1995, p. 27). There is a lack of clarity, not a lack of information. The information says many things; it is subject to varying interpretations. To one ERT participant, the information may show ATC to be the primary contributor to the event. To another participant, the same information may show the flight crew to be the primary contributor. And so on.

Safety theory suggests that uncertainty and equivocality are best addressed through diversity of personnel and viewpoints. Complex events, and what they imply, can be understood only by looking at the situation from different viewpoints and then discussing it.

Since events and accidents are often novel and confounding (even considered "impossible" before they occurred) investigators must have "requisite imagination, a diversity of thinking and imagining that matches the variety of possible failure scenarios" (Reason 1997, p. 38, acknowledging Westrum). In the resulting dialogue, experts point to cues that they believe are important indicators of what really occurred, and what the occurrence reveals about present and future conditions. For instance, ERT experts routinely discover a key error in a complex event report such as one person forgetting to tell another something. From this, they may make a more general inference: there is excessive time pressure in a particular situation, and not enough crosschecking. The ERT then extrapolates to possible consequences, and decides whether the situation requires corrective action.

Klein has suggested that experts ranging from physicians to naval commanders have powerful mental models that allow them to both explain the past and predict the future $(1998$, p. 46-58). Our observations of the ERT suggest that the participants have very rich, and complementary, mental models of the aviation domain. ${ }^{3}$ The participants are able to replay the events in their minds, and then share these explanations and solutions with their collaborators. The variety of the ERT also restrains our human tendency to "invent an explanation that discounts some inconvenient observations" (Klein 1998, p. 68).

The search for cues is shown in this illustrative dialog, assembled from samples of discussions that we observed:

Team member A: [reading] We've seen this before.

Team member B: Maybe not. Notice this... [draws attention to certain cues]

\footnotetext{
${ }^{3}$ The fact that many of the ERT participants are active, commercially rated aviators suggests both the depth of this expertise and the need for its constant exercise.
} 
Team member $\mathrm{C}$ : Now that you put it that way, I see what you mean. We need to do something about this.

Team member A: Let's keep it for next week. I'll make some calls and find out more about... [cues]

Team member B: Good. [all members make notes]

The assembled expertise of the ERT allows them to spot leverage points, described by an Israeli general as "a small difference that makes a large difference" (Klein 1998, p. 111). In the complex aviation domain, such points can be subtle hazards but also opportunities. For instance, the ERT may be able to take corrective action that protects against a hazard, reduces the impact of the hazard if it penetrates the protection, and reduces costs.

Weick observes that in management "quick responses [can] shape events before they have become crystallized into a single meaning" (1995, p. 57). As observers, we perceive the ERT as a quick response team. Because of its expertise, and the checks and balances of the diverse team members, the ERT can take judicious actions that avert disasters. In some cases, this is as "simple" as drawing attention to a problem that no one has seen or thought important.

ERT activities in no way reduce the importance of the FARs and long-term trend analysis. They are highly complementary and mutually supporting. In some ways they are analogous to primary care medicine and epidemiology. An ERT can respond quickly to emerging, localized problems (in days or weeks) while trend analysis and the FARs detect and respond to long-term, widespread changes.

The ERT looks for cues in complex phenomena

The ERT uses its combined perspective to seek out the cues that reveal underlying causes of complex events. These causes include:

- Latent conditions, "such as poor design, gaps in supervision, undetected manufacturing defects or maintenance failures ... may be present for many years before they combine with local circumstances and active failures to penetrate the system's many layers of defenses" (Reason 1997, p. 10). Event reports may be the glimpse that reveals a latent condition that has been missed.

- Changes producing new hazards in the environment, especially those from combinations of factors that could not have been foreseen by system designers (Leveson 1995, p. 100). Modifications to aircraft, airports, air routes, and procedures may interact in very complex and subtle ways to produce new hazards or increase existing hazards.

- Interface problems that occur between organizations or their departments, e.g. Flight and Maintenance. Because interfaces are not anyone's primary focus, they are universal problem zones. For example, in one study of the steel industry, " $67 \%$ of technical incidents with material damage occurred in zones of co-activity” (Leveson 1995, p. 203, citing Leplat). 
One of the key roles of the ERT is system change detector and interpreter. Based on his studies of high hazard domains, Weick has noted that "interruption of standard operating procedures is [often] a signal that important changes have occurred in the environment" (1995, p. 46). Yet, skilled people are adaptable enough that they may compensate temporarily for these interruptions. The event report may be an opportunity to discover these changes before compensation fails and large consequences result.

We have outlined how, by adopting different points of view, the ERT finds cues and meanings in events. But there is still the problem of conflict. Agreeing on meaning is often difficult, but not as difficult as agreeing on action. The test point of unanimous consensus must be passed.

\section{A tilt-table model of ERT collaboration}

As observers, we have developed a model to think about the fast-paced, complex interaction of the ERT. We envision the ERT meeting as centered around a triangular table (Figure 4). At each vertex are the representatives: FAA, air carrier, APA. Each person has social links to an organization and one or more cultures. These links are the person's identity, established through professional upbringing, training, and work experience.

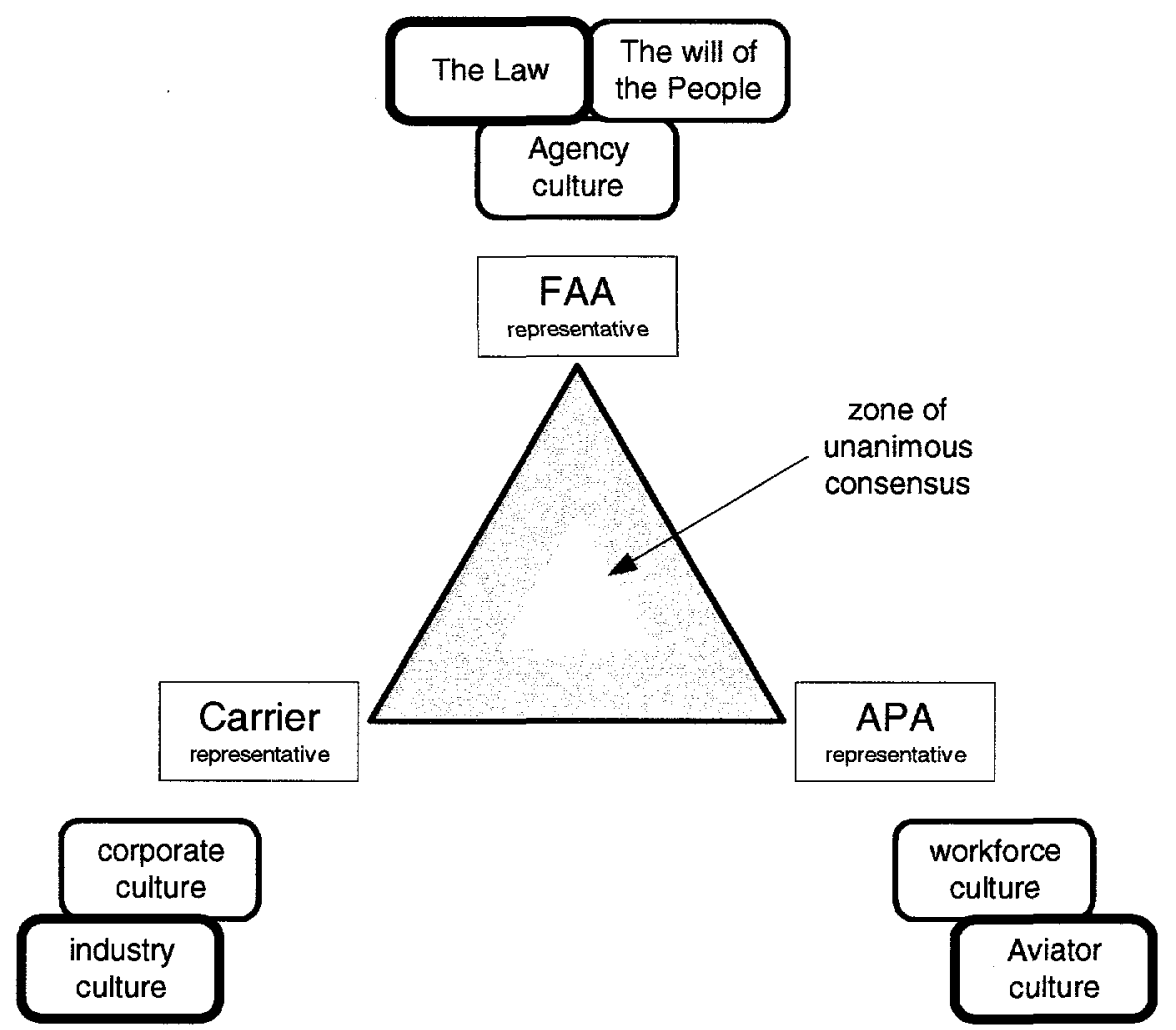

Figure 4. A tilt-table model of the ERT. Each participant feels the influence of his or her constituents. Reasonable compromises are reached so that action can pass through the zone of unanimous consensus. 
Potential corrective action can be visualized as a steel ball on the table. In order for this potential action to be implemented, the ball must pass through a hole at the center: the zone of unanimous consensus. The representatives must cooperate in achieving a reasonably balanced table.

The constituencies exert strong forces on the representatives. When the FAA representative, for example, makes judgments and decisions he or she feels the weight of the agency, the people of the United States, and ultimately, the law. These forces compel the representative to tilt the table towards themselves and what they represent.

Yet, if the representative tilts the table too much, the potential action misses the center zone. How do the representatives reach unanimous consensus when, from identities alone, they are in fundamental conflict?

\section{Achieving table balance: The AA-ASAP Hierarchy of Values}

Culture is the set of beliefs and priorities that a group of people share. These tacit agreements allow people to act in unison to achieve goals.

Our observations suggest that the tilt-table is balanced through shared priorities. The ERT participants temporarily set aside their differences in favor of their similarities. During the meeting, they give the value "We are professional aviation experts" a higher rank (Rank 1 in Table 1) than "I am a representative of a particular organization and culture" (Rank 10 in Table 1). The return on investment from this action is movement (corrective actions) towards shared goals.

Table 1. The AA-ASAP Hierarchy of Values

\begin{tabular}{|c|c|c|}
\hline Rank & Value & Observer interpretation \\
\hline 1 & We are professional aviation experts & $\begin{array}{l}\text { We are skilled people who value } \\
\text { successful outcomes in an uncertain } \\
\text { environment. }\end{array}$ \\
\hline 2 & Aviation is a team endeavor & $\begin{array}{l}\text { Aviation depends fundamentally on } \\
\text { cooperation }\end{array}$ \\
\hline 3 & $\begin{array}{l}\text { We must take corrective actions in order to improve } \\
\text { performance }\end{array}$ & $\begin{array}{l}\text { Analysis without action is of limited } \\
\text { value }\end{array}$ \\
\hline 4 & We must discover the conditions that underlie events & $\begin{array}{l}\text { Causes are not always obvious even to } \\
\text { experts }\end{array}$ \\
\hline 5 & $\begin{array}{l}\text { Learning about events is often more important than } \\
\text { placing blame }\end{array}$ & $\begin{array}{l}\text { Punishment (enforcement) is essential } \\
\text { to, but not sufficient for, safety in the } \\
\text { aviation domain }\end{array}$ \\
\hline 6 & Aviation is a complex and dynamic undertaking & $\begin{array}{l}\text { Latent conditions and new hazards are } \\
\text { often extremely subtle and can only be } \\
\text { detected with a broad collection net }\end{array}$ \\
\hline 7 & Aviation requires performance under pressure & We have the "Right Stuff" \\
\hline 8 & No one viewpoint on events is completely correct & What does this event mean to you? \\
\hline 9 & $\begin{array}{l}\text { We must compromise and reach an equilibrium before } \\
\text { corrective actions can be taken }\end{array}$ & What can we agree to do about this? \\
\hline 10 & $\begin{array}{l}\text { I am a representative of a particular organization and } \\
\text { culture }\end{array}$ & $\begin{array}{l}\text { I am held accountable by those I } \\
\text { represent. They are not present, but I } \\
\text { feel their influence. }\end{array}$ \\
\hline
\end{tabular}


When the hazard of deadlock looms, the higher values come into play: We are all aviators. Aviators get things done. Unanimous consensus is achieved, and the ERT moves forward to the next event.

The shared values hierarchy seems to be the common anchor that allows the individual team members to reach the unanimous consensus test point.

Note that this value hierarchy is specific to one setting: the ERT meeting. We are not implying that AA-ASAP has changed participant's identities or loyalties, or that it could. Instead, participants temporarily reshuffle their hierarchies in order to make the team function for mutual benefit. The ERT meeting evokes certain priorities and repertoires of skills from a participant (March 1994, p. 249).

\section{Sideband communications}

When the ERT gathers, they form a working buffer around themselves (Figure 5). This buffer helps the team members to concentrate on their shared identity as a team. The constituencies are never forgotten, but their influences are buffered. The meeting room with its somewhat neutral setting and lack of interruptions helps to form the buffer, as does the professional trust that develops among the team members.

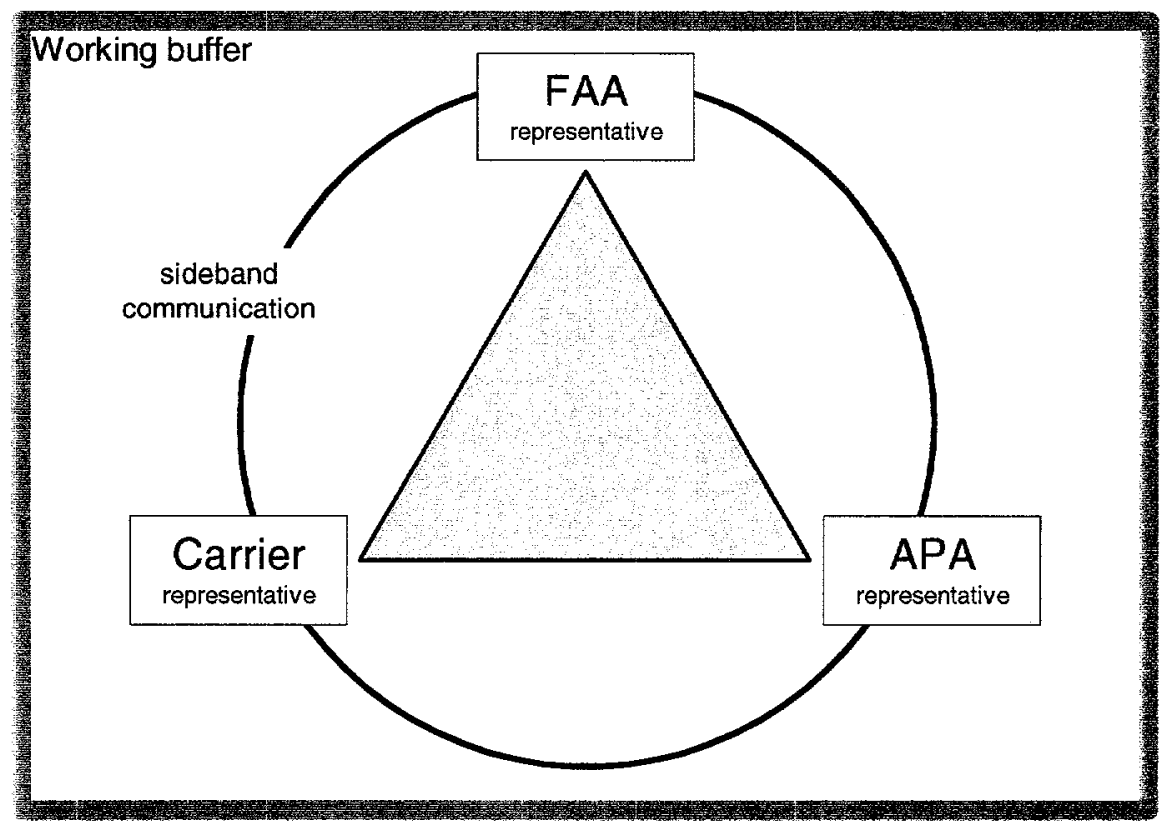

Figure 5. The ERT tilt-table with a working buffer that reduces the influence of the constituencies (see Figure 4) so that pragmatic agreements can be reached. Sideband communication allows the participants to build trust that improves their ability to reach unanimous consensus. 
If the ERT is an engine governed by unanimous consensus, then trust among team members is an essential lubricant. Trust raises the efficiency that allows the team to move through a large number of reports, while conserving energy to address the most important ones.

In our observations, trust is built largely through sideband communications that take place around the periphery of the tilt-table (see Figure 5). Sideband communications are not directly about the facts of an event. They concern the members as individuals. They serve as subtle reminders of the member's constituencies and viewpoints. They also serve as reminders of the shared hierarchy of values (see Table 1).

In our view, the most important sideband communication content is humor. Humor serves as a pressure valve and a way of making graceful demands and concessions. Humor can be used to acknowledge and then pass beyond conflicts between constituencies (e.g., legal wranglings between the carrier and the APA). While humorous exchanges make up a small percentage of the meeting time, they have an importance out of proportion to their time consumption. Humor seems to provide a trim function. After a contentious event discussion, humor brings the team back to reasonable neutrality so that they can move forward without leftover emotions affecting the next discussion.

The word penalty is an AA-ASAP structure that depends on a shared sense of humor. If a participant inadvertently utters a bad word, they are compelled to place one dollar in a kitty on the table. When the kitty grows to a certain size, it is donated to a charitable cause. The kitty, and opportunities for its enlargement, are monitored closely by the ERT coordinator.

The word penalty implements a very serious set of ERT rules: Stay cool, stay civil, and stay productive. We have many more events to work through today. These important rules are enforced informally, rather than formally. The word penalty allows a graceful way out of a slip. The team shares a laugh as the person sheepishly adds to the fund. Conflict can be diffused before it damages the overall process.

\section{AA-ASAP Benefits}

The FAA ASAP is intended "to increase the flow of safety information to both the air carrier and FAA" (FAA AFS-200, 1997). Has AA-ASAP approached this ideal? Much of the answer is suggested by the large number of events that AA-ASAP has handled; approximately 17,000 between 1994 and 1999 (McKenna, 1999b). AA-ASAP participants believe that less than one percent of these events would have come to light without the program.

When ASAP is scaled-up to include other carriers, the increased sample size and interaction may help to address calls for more sharing of lessons-learned (e.g., Duke, 1999; McCartney, 2000).

Besides taking corrective action, the carrier is using AA-ASAP information in the larger system safety lifecycle. Eight of nine human factors training scenarios at the American Airlines Academy are based on AA-ASAP events. 
AA-ASAP has provided many opportunities to address the complex and subtle flaws inherent in large technological systems like the aviation domain. These include new hazards that have arisen from combinations of factors and interface problems that are not the focus of any particular department.

Publication of selected events and actions is an essential requirement of FAA ASAP. AA-ASAP publications and display materials have helped to raise and renew awareness of subtle, omnipresent hazards, including complacency. These remind all personnel that the "unrocked boat" (Reason 1997 , p. 6, acknowledging Perin) or unbuffeted aircraft is always surrounded by hazards.

FAA ASAP recognizes that publication of real world, credible lessons is more effective than simply exhorting people to "Think safety." In our information-saturated society, stories from peers seem to get attention.

Skilled personnel often develop habits and shortcuts that seem advantageous and low risk. But ASAP increases the sample size beyond what one person can experience. An individual can understand that succeeding in an action is not a guarantee of long term safety. This helps to avoid the fallacy of centrality: "Because I don't know about this [trend], it must not be going on" (Westrum in Weick 1995, p. 2). Publications can stimulate a realization by personnel: That could have been me.

AA-ASAP appears to have significant secondary effects. One comes from the actions of the fact finders. A call from a fact finder may elicit information for the ERT, but it also leaves an implicit message for the recipient of the call: The organization is acting on safety. Somebody cares.

Somebody is watching. The probes of the fact finders help to show lower levels in the organization that higher levels are taking real action on safety (Leveson 1995, p. 68).

The FAA also derives indirect benefits from AA-ASAP. While the FAA representative cannot use ASAP information or evidence to take enforcement action, there is no prohibition on carrying away new ideas for enforcement (such as where to look for infractions tomorrow) and regulatory practices. Seeing such a broad sample of events may also help FAA personnel to take a proactive, system-oriented approach to safety.

\section{AA-ASAP Costs}

AA-ASAP shows some of the costs of ASAP in general. Some resources are taken from enforcement activities. However, these costs seem to be far outweighed by ASAP's net effect on safety.

There is also some concern about diminishment of FAA authority. Our observations suggest that ASAP can actually enhance the FAA's authority. It can provide new ideas for law enforcement and punitive action. Observation of ASAP meetings could become a part of the training of FAA inspectors. Most importantly, ASAP helps FAA personnel to address the other face of law and regulation: the way things ought to be. 


\section{Conclusions}

We began by outlining the ASAP philosophy: encourage voluntary reports of safety-related events so that corrective actions can be taken. The core of ASAP is the ERT, whose members are in conflict but work together as a productive team to analyze events. The team must discern meaning in complex events, overcoming both uncertainty (lack of information) and equivocality (lack of clarity). At each event, the team faces a recurring test, unanimous consensus, that maintains the stability of the overall process. We model the ERT interaction using a tilt-table metaphor. The members must achieve a reasonable balance of views in order to take action. We suggest that this balance is achieved when members adopt a shared set of cultural priorities where productive action is paramount. Sideband communications, particularly humor, allow the ERT to construct a working buffer around its members and to interact effectively and efficiently.

While having innovative features, ASAP in all its forms seems aligned with both classical theories of administrative action (e.g., Simon 1945/1997) and emerging outcome-based safety philosophies (e.g., Reason 1997). The program is a process for collecting and acting upon events that have been likened to "free lessons" (Reason 1997, p. 119, acknowledging Exxon).

The goal of FAA ASAP as a test program is to discover both flaws and innovations that can be, respectively, corrected and possibly incorporated into the program. As observers, we believe the unanimous consensus is an important operational discovery by AA-ASAP. It serves the vital role as "trim function" for the long-term trajectory of the ERT.

ASAP is an important and promising demonstration of FAA leadership and its willingness to work collaboratively with industry for the public good. 


\section{References}

AA-ASAP. 1998. Aviation Safety Action Partnership (ASAP): Letters of agreement between American Airlines, Federal Aviation Administration, Allied Pilots Association, and Transport Workers Union.

Duke, Tom. 1999. Safer Skies require mindset change (Guest Editorial). Aviation Week and Space Technology, 25 October 1999.

FAA AFS-200 (William J. White). 1997. Advisory Circular 120-66: Aviation Safety Action Programs (ASAP). 1-8-1997. http://www.faa.gov/avr/afs/acs/120-66.txt

Grey, Jerry. 1999. To make skies safer, focus on pilots (Guest Editorial). The Wall Street Journal, 3 November 1999.

Griffith, K. Scott and David Marx. 1998. Viewpoint: To improve air safety, focus on incidents, not accidents. Aviation Week and Space Technology, 13 July 1998.

http://www.awgnet.com/safety/news/nz072098.htm

Helmreich, Robert L. and Ashleigh C. Merritt. 1998. Culture at Work in Aviation and Medicine: National, Organizational, and Professional Influences. Ashgate Publishing.

Klein, Gary. 1998. Sources of Power: How people make decisions. MIT Press.

La Porte, Todd R. 1996. High Reliability Organizations: Unlikely, demanding, and at risk. Journal of Contingincies and Crisis Management 4(2), June 1996, pp. 60-71.

Leveson, Nancy G. 1995. Safeware: System safety and computers. A guide to preventing accidents and losses caused by technology. Addison-Wesley.

McKenna, James T. 1999a. Carriers, union race to salvage safety efforts. Aviation Week and Space Technology, 25 October 1999.

McKenna, James T. 1999b. FAA, Industry to press for data-sharing pact. Aviation Week and Space Technology, 1 November 1999.

March, James G. 1994. A primer on decision making: How decisions happen. Free Press.

Mathews, Anna Wilde. 2000. FAA to back reporting of safety lapses. The Wall Street Journal, 14 January 2000.

McCartney, Scott. 2000. Airline industry debates need for uniformity on pilot rules. The Wall Street Journal, 14 March 2000.

Perrow, Charles. 1984. Normal Accidents: Living with high-risk technologies. Basic Books. 
Reason, James. 1997. Managing the risks of organizational accidents. Ashgate Publishing.

Rochlin, Gene I., Todd R. La Porte, and Karlene H. Roberts. 1987. The self-designing highreliability organization: Aircraft carrier flight operations at sea. Naval War College Review 40(4), pp. 76-90.

Simon, Herbert A. 1945/1997. Administrative Behavior: A study of decision-making processes in administrative organizations. $4^{\text {th }}$ Edition. Free Press.

Weick, Karl. 1995. Sensemaking in organizations. Sage Publications. 


\section{Distribution:}

0188 Bryon Cloer, 12113

0449 Judy Moore, 6234

0451 Ron Trellue, 6238

0451 Jennifer E. Nelson, 6235

0490 Perry D'Antonio, 6231

0490 John Covan, 6231

0490 Arlin Cooper, 6231

0490 Paul Werner, 6231

0490 Mark Ekman, 6231

0615 Roger Hartman, 6252

0615 Casey Jones, 6252

0615 Dick Perry, 6252

10612 Review \& Approval Desk, 9612

For DOE OSTI

0619 Patty G. Guyer-Stevens, 12620

0639 Robert Goetsch, 12303

0741 Samuel G. Varnado, 6200

0747 Alan Camp, 6412

0829 Kathleen Deigert, 12323

0829 Chris Forsythe, 12323

0829 Caren A. Wenner, 12323

0829 Marcey Abate, 12323

0839 Elaine M. Raybourn, 16000

20899 Technical Library, 9616

1137 Kathie L Hiebert-Dodd, 6535

1137 John Mitchiner, 6534

1137 Craig Dean, 6535

1138 Bruce N. Malm, 6531

1138 Eunice Young, 6532

1140 James K. Rice, 6500

1140 Larry J. Ellis, 6510

1211 Dori Ellis, 5300

1215 Henry Abeyta, 5300

1219 Annette Sobel, 5907

1221 Russell D. Skocypec, 15002

9105 Howard Hirano, 16000

19018 Central Technical Files, 8940-2 